Please quote as: Do Student-Instructor Co-Created eLearning Materials Lead To Better Learning Outcomes? Empirical Results from a German Large Scale Course Pilot Study. In: 45. Hawaii International Conference on System Sciences (HICSS), Hawaii, USA. 


\section{Do Student-Instructor Co-Created eLearning Materials Lead To Better Learning Outcomes? Empirical Results from a German Large Scale Course Pilot Study}

\author{
René Wegener \\ Kassel University, Information Systems \\ wegener@uni-kassel.de
}

\author{
Jan Marco Leimeister \\ Kassel University, Information Systems \\ leimeister@uni-kassel.de
}

\begin{abstract}
Universities in Germany face increasing numbers of students, while resources are stagnating or shrinking. Especially large scale lectures suffer from a lack of individualization and interaction, often leading to inefficient learning outcomes and low student satisfaction. We present the concept of instructors co-creating eLearning modules and even parts of the exam with students for improving learning outcomes and student satisfaction. Following an action research approach, we developed, applied, and refined the concept in a mass lecture course setting over four semesters. Evaluation of questionnaires and exam results show that our concept leads to a significant increase in perceived learning satisfaction and learning outcomes. This paper outlines and tests new ways of enhanced learner integration into learning service delivery. It shows the actual impact of student integration into learning content creation, both on service quality and learning outcomes while taking resource efficiency into account.
\end{abstract}

\section{Introduction}

The OECD (Organisation for Economic Cooperation and Development) claim that investments in the educational sector influence the productivity of an economy, and thus have a high return on investment for society [28]. However, the German education sector suffers from a lack of finances and resources [38], especially since the numbers of students have been increasing for several years and are expected to grow even further during the next years at a possible ratio of $25 \%$ [25]. Thus, delivering a qualitative learning service fitting to individual needs becomes more and more difficult.

eLearning materials offer the opportunity of increasing individuality and quality of the learning process by encouraging students to learn at their own pace. To implement eLearning, however, instructors

\footnotetext{
${ }^{1}$ Parts of this research were funded by the German Federal Ministry of Education and Research in the project BlendedContENT (www.blendedcontent.de), FKZ 01PF08022A
}

may have to re-design courses, create content, administrate learning platforms, offer students advice, and assess learning outcomes [15]. They have to switch between roles of affective (creating a good atmosphere in the classroom), cognitive (helping students achieve learning goals) and managerial (creating, delivering, and assessing the course from an organizational perspective) tasks [8].

Considering this situation, we need to look for new ways of delivering a high quality learning service that takes into account the possibilities of new media, didactical needs, and economic constraints. Web 2.0 platforms, such as Wikipedia, show that content creation does not exclusively depend on single domain experts. In addition, many people feel motivated when contributing to a product like a Wiki. However, in educational contexts we need the right processes and tools that support students in content creation while still providing a guarantee of high quality. With intelligent integration of students' minds and information technologies, these goals can be achieved while leveraging the instructor, thus helping to deal with stagnating resources.

This paper presents the results of a case study that was based on a traditional, instructor-centered, large scale lecture, but was successively enhanced with more interaction and student created eLearning modules over a period of four semesters. The main measures taken were the following:

1. Introducing small tasks during the lecture by letting students create their own true-falseitems with regard to the course content that could later be used in the exam, and

2. Supplementing learning materials through a videoconferencing consultation hour, a video broadcast and interactive web based trainings (WBTs) that were implemented not by the instructors but by the students themselves.

The goal was to enhance the course in two ways: First, we wanted to offer students a better service with higher perceived quality. Second, we wanted to raise the actual learning outcomes. To evaluate the achievement of objectives, the course was evaluated after each semester with the help of online questionnaires and a comparison of exam results. 
The rest of the paper is structured as follows. The next section introduces related didactical and economic basics. The background of the case study and the research methodology are described in the third section. The fourth section outlines the evaluation tools before the results are presented. The paper ends with conclusions, limitations, and recommendations for future research.

\section{Related work, didactical and economic context}

The goal of our research was to improve a large scale course with regards to learning outcomes and learner satisfaction with economically reasonable measures. This required converging the two different and sometimes conflicting perspectives of economically oriented educational and pedagogical control [26]. The next paragraphs briefly explain didactical basics, as well as the economic challenges, from a service delivery perspective.

\subsection{Understanding the learning process}

At its core, learning is a change of the state of the human being expressed in a change in the individual's behavior based on experiences [13]. When the process of learning is supported by information and communication technologies, we talk about electronic learning or the more common "eLearning" [20].

Experiences that trigger learning processes are gained through different ways of interaction, e.g., with content or between learners [35]. Learners actively look for meaning in things [5] and construct their own understanding of the world. Knowledge is viable as long as it fits with experienced reality. When it comes to testing and adapting one's knowledge, social interaction plays an important role: learners need the opportunity to discuss and reflect on their opinions $[1,6,14]$. In this way, knowledge is co-constructed through a permanent process of divergence and convergence, where learners iteratively adjust their understanding.

While this principle describes the learning process at its core, learners differ much with regard to their experiences, personal needs, desires, and preferred individual learning styles [23] e.g., a more passive consumption of knowledge, visual representations, or active engagement in real world scenarios. Offering eLearning modules helps learners work at their own pace and choose the way in which they want to interact with contents [19]. Thus, a learning scenario should offer different sources of knowledge acquisition and different ways of interaction with peers, the instructor, and the learning materials.

\subsection{Teaching as service delivery}

While a learning arrangement is planned with regard to didactical aspects at its core, one also has to keep in mind that delivering a lecture is a resource demanding service. When taking into account the different phases of the service delivery [9], resources are needed for the potential dimension as well as the factor integration. First, instructors have to keep available contents, methods, technologies, and everything else they need for delivering their course. Second, the delivery process itself demands that instructors spend their or their team's time on the lessons themselves, adjusting materials, and supporting or assessing students.

This leads to the question of which parts of the teaching service can now be standardized, automated or delegated to the customer (the learner) in order to save resources without reducing the perceived service quality. While new technology does allow offsetting face-to-face lessons, service research clearly states that face-to-face contacts are a crucial part of service delivery, impacting also perceived quality [11]. These thoughts are supported by learning theory, which stresses the importance of social processes.

However, when splitting the teaching process into several parts, some sub-processes that demand most resources can be automated or delegated to the learner [37]. For example, learners spend a lot of time with self-regulated learning. They recapitulate contents of the lecture with the help of the script or whatever learning materials are offered. For this reason, cost efficient ways of creating high quality learning materials are very beneficial for students.

\section{Background of the Action Research project}

The research presented here was conducted at a German University in the course "Introduction to Business Informatics" aimed mostly at students of business administration and economics. The course is offered each semester with 150 to 300 participants. It was planned and implemented as a traditional frontal lecture supplemented by small-class tutorials with graduate assistants. Students are graded by the scores of a written exam at the end of a semester. We wanted to increase learner satisfaction, as well as learning outcomes, without using too many (or at best no) additional resources. To achieve our goals, we went through the typical steps of action research. 


\subsection{Methodological approach for the Action Research project}

Typically, action research focuses on evaluating measures in real life situations to solve specific problems, and is divided into five specific steps which are taken iteratively [34]: diagnosing, action planning, action taking, evaluation, and specifying learning. We followed these steps and tried to improve our concepts and tools after each semester, before restarting the cycle from the beginning. With regard to the case study, the five steps included the following.

Diagnosing: First, we analyzed our current situation and the problem $/ \mathrm{s}$ we were facing. In general, the large scale lecture was lacking interactivity and individuality. In addition, we were expecting increasing numbers of students, and thus had to look for ways of raising the level of interaction and individuality without needing to use more resources. As a first step, we used methods from the Service Engineering domain, such as Service Blueprinting [37], to identify critical parts of the learning and teaching process. We identified two main challenges. First, interaction is one key element for learning and learners' satisfaction. There are different types of interaction, the most important being learner-learner, learner-instructor, and learnercontent interaction $[27,35]$. In the current situation, there was nearly no learner-learner interaction during the lecture and just a slight level of learner-instructor interaction when the instructor asked some questions. In addition, learner-content interaction was mostly focused on a traditional script, offering not much diversity or visual appeal. Second, a major challenge in teaching is addressing the students' different learning speeds and styles. Students differ in the sensory channels through which they best perceive information and also their preferred learning method: inductive or deductive [10]. Thus, we also wanted to offer a wide range of high quality learning materials that students could freely choose from for self-paced learning.

Action Planning: The new learning materials should be more appealing, highly interactive, and diverse. In this context eLearning materials offer the advantage of self-paced learning as well as stimulating different ways of perception. As stated by other authors, we hoped that a higher degree of learner control might lead to better learning outcomes [32]. But because development of eLearning materials takes a lot of time, we decided to involve our students in the creation process based on the idea of "learning through teaching" [17]. According to this idea, learning can be supported by students switching to the role of a teacher. A student acting as a tutor has to reflect deeply on the content he wants to teach. In addition, explaining things to others requires skills with regard to creativity, selfconfidence, and communication. We adapted this idea onto the creation of eLearning materials within the framework of a seminar on "Web Engineering." After the "Introduction to Business Informatics" course, students could choose to take part in this course. Since they were supposed to learn the basics of Web Engineering with Flash, this course was ideally suited for allowing students to create interactive eLearning modules. This measure will thus be the focus of our paper, explained in greater detail in the next section.

These Web Based Trainings (WBTs) were supplemented by videos of the lecture offered as live streams, as well as records stored on the learning management system (LMS). While the videos were not user generated, they offered the possibility of creating learning materials quickly and at low cost.

In order to raise the interaction in the classroom, two small assignments were integrated into the 90 minute lecture. At two times in each lecture, students were asked to create "true-false-items" with regard to the contents they had just learned. These items were exchanged, discussed, and revised between the students, and then delivered to the instructor. The best items were used in the exam at the end of the semester. The idea behind this is that students' attention declines during a teacher centered lecture, and active breaks help them to re-engage as well as reflect on what they have just learned [29].

Action Taking: Delivery of the lecture as a video stream was easily implemented, thanks to the central LMS of the university. The assignments where students created their own "true-false-items" were also easily integrated into the course, since no additional material was needed for this. The challenging task was to get students from the Web Engineering lecture to create high quality eLearning modules that would deliver a real benefit to their peers. The first eight WBTs were used in the first semester, and then supplemented or exchanged by further WBTs during the next semesters. The content production process is outlined in detail in the next section.

Evaluation: Evaluation focused on the students' satisfaction as well as learning outcomes. Data were collected from two sources: 1) online questionnaires that students filled out at the end of the semester immediately before the exam, and 2) the results of the exams with regard to the score students had 
achieved were compared in order to measure learning outcomes.

Specifying Learning: After the evaluation, measures were taken again in order to improve the learning scenario further, e.g., the creation process of the WBTs was adjusted in order to generate more appealing and interactive eLearning modules for the next semester.

\subsection{Integrating students into content production}

\subsubsection{Creating true-false-items during the lecture}

Students were involved in the process of content production in two different ways. First, as mentioned, they created true-false-items during the lecture, a method entitled: "Co-Create Your Exam." During traditional classroom teaching, there is the tendency for students' attention to drop from time to time; however, small breaks of about two to three minutes are helpful to regain their attention. Olmsted [29] suggests several types of "active breaks," including assessments or feedback. We wanted to focus on one method so that students would not have to adapt to different ones. However, we chose to combine the assessment with the feedback. By letting students create their own true-false-questions, the instructor would get insights into what content students struggled with or had already understood (considering that students would probably focus only on stuff they felt they had understood well). On the other hand, by having students pass the questions to their neighbors and solving them, there was a sort of peer assessment which can foster learning by teaching since it supports critical discussions between students [36].

The implementation was very simple. After about 30 to 60 minutes, the instructor advised the students to take a sheet and write down three statements dealing with the content they just heard. At least one of those statements had to be true and one false. After a few minutes, students exchanged their sheets and tried to answer their peer's questions. The students also had the opportunity to discuss answers or adjust what they had written. The sheets were then collected by the instructor, who would later select some of the items as part of the final exam, and some were uploaded on the LMS in electronic format.

In this way, one of the core principles of learning, the social exchange, is introduced to the large scale lecture. In addition, the process does not demand any resources from the instructor, except choosing the best items for the exam. Creating similar items would surely take at least the same amount of time. Apart from that, the created items could even be used as supplementary learning materials in future semesters.

\subsubsection{Creation of web based trainings}

The creation of the WBTs was a very complex process. A WBT is an encapsulated eLearning module that can be used for self-regulated learning. It offers all the advantages already discussed in the background section. Students can learn at their own pace, anytime, anywhere. The materials can also stimulate different senses by use of video, audio, and textual information, which can offer much more interaction than do paper based materials. The dynamics of the media also allowed for animations that could aid understanding of complex processes.

But all these advantages are in effect only if the materials are created properly. The materials need to take advantage of the potentials of the medium, be didactically sound, and have flawless contents.

The underlying concept of what we did is called learning through teaching $[17,16]$. When being responsible for explaining things to their peers, students are expected to engage at a deeper level and improve their communication skills. But the students need to be guided in this. The seminar "Web Engineering" was thus extended with some didactical basics. In addition, the students received guidelines on how a WBT could be structured, which common mistakes should be avoided, or how interactive assignments could be implemented. They also received a standardized layout for the WBT, along with several examples of animations or assignments they could adjust and use in their own modules. In this manner, we could guarantee that all trainings had the same look and feel, as well as basic common features.

The general topics of the WBTs were predetermined by the instructor, and all dealt with the lecture "Introduction to Business Informatics." However, the students were offered a great deal of freedom in setting the focus and creating new kinds of animations or assignments.

The process of implementation of WBTs started with students creating a storyboard. This was reviewed by an instructor with regard to the learning goals and first impressions. A second storyboard was then developed and again reviewed. Based on this final review, the students then implemented the actual WBT.

Further, students of the Web Engineering course were introduced to the technical basics of Flash and Web Programming in several lessons. The course was based on much self-regulated learning. The 
instructors were asked to offer their students considerable freedom when creating the WBTs, since too much instruction would not lead to greater motivation and deeper learning processes [2]. To facilitate the development process, the instructor regularly posted hints and templates, or answered questions, thus showing constant presence [31, 22]. Apart from general tips and advice, the instructors always offered direct $1: 1$ feedback on questions or products such as storyboards, as direct feedback is crucial for motivating learners [21].

This process was iteratively improved by instructors. For example, many students faced problems when planning their WBTs addressing learning goals that were higher than just pure knowledge acquisition [3]. Even when it came to teaching modeling techniques - a basic skill in Business Informatics - students often relied on simple multiple choice tests as assignments. After realizing the problem, the instructors offered a new template for implementing modeling tasks into the WBTs, thus enabling learners to compose whole diagrams on their own, instead of just answering simple questions. This is just one example of how the content production process was gradually improved. During the fourth semester, part of the feedback that the instructors gave on the WBTs was exchanged for peer-reviews. In this way, even more responsibility was later delegated to students. During the feedback phase students could take a look at other's WBTs and point at good ideas or flaws. Peer assessments have proven to be quite reliable in identifying strengths and weaknesses of students' learning products [36]. The peer review process was also scaffolded by a guideline given to the students that was intended to encourage them not just to identify their peers' mistakes, but also to offer open-ended and suggestive feedback, as implied by Topping [36].

The final WBTs were assessed by instructors who chose which ones were suitable for being used in the lecture. These WBTs were then finalized by instructors by identifying and deleting the last flaws concerning content or technical implementation.

The content was kept up-to-date in two ways. Smaller changes were implemented by the teaching staff and the research assistants. If there was need for major changes in a WBT, it was completely exchanged with a newer one. This was possible due to the fact that the general topics of the WBTs were determined by the teaching staff, and each semester new WBTs were created by the students.

\section{Evaluation}

\subsection{Methodological Aspects}

Deriving statements on the efficiency of the different actions aimed at increasing learning outcomes and learner satisfaction requires defined reference measures not only for the success of each single action but also for all combined actions (in this case, measures for the success of the entire blended learning course). However, in field research it is difficult to define success measures or cause-effectchains for single actions / interventions, as these affect the users both independently and in combination with other actions; therefore, their impact cannot be regarded in isolation. Often it is only possible to measure and evaluate the sum of several actions and influences as a whole.

For the proposed formative evaluation, we used self-reporting data sources (online surveys). Choosing an online survey as a method to collect data poses some important consequences for the process of the investigation and for the design of the questionnaire (for further details see $[12,4]$ ). Some basic problems generally occur when conducting online surveys. The sample is self-selected, since evaluation participation is voluntary, and therefore cannot be regarded as being representative; thus, statements about "non-participants" cannot be made [18]. The questionnaire used in this study was structured, tested, and consequently adapted to the needs of the specific targeted audiences. For this purpose, a pretest, followed by a discussion with the test persons, was conducted. In addition, an onlinepretest was carried out, which tested the content and the functionality of the questionnaire.

\subsection{Evaluating students' satisfaction}

We wanted the students to be satisfied with their learning experience, and for this reason, we used the questionnaire to keep track of their levels of satisfaction. Since the course at its core was a typical large scale lecture, part of the items for the questionnaire were developed with regard to traditional dimensions of learner satisfaction [7]. These six dimensions focused mainly on the instructor and course as a whole. The dimensions were: skill level of the instructor, instructor's rapport (empathy and friendliness), course structure, course difficulty, interaction, and feedback. The last dimension referred to whether the instructor told students about their learning progress or gave them feedback on their task performance. Since this was a large scale lecture demanding a lot of self-regulated learning without direct feedback from the instructor, this dimension was excluded from the questionnaire. 
The second part of the questionnaire was supplemented by dimensions taken from eLearning success models. Since the course offered a great deal of eLearning materials, we wanted to take the eLearning parts into account separately. However, there were some technological aspects that could not be changed by the instructor. For example, the LMS or technical infrastructure could also be evaluated, but since both were maintained by the University itself, there was no possibility of improving these factors for the instructor. Thus, only factors that the instructor was in charge of were taken into account. These factors focused on the different virtual learning materials and included their technological quality (like the look and feel), their flexibility, and their usefulness in the learning process $[33,30]$.

All items were rated on a Likert scale ranging from 1 (full agreement) to 5 (no agreement). Table 1 provides an overview of the items.

Table 1. Satisfaction questionnaire items Course - General

(1) Satisfaction with course in general (2) Satisfaction compared to other lectures (3) Innovativeness (4) Overall recommendation

\section{Course - Structure (overall)}

(1) Overall structure (2) Contents in general (3) Relevance for praxis (4) Learning materials in general (5) Clarity of performance requirements

\section{Instructor - Skill Level}

(1) Satisfaction with instructor in general (2) Knowledge of the instructor (3) Helpful explanations of the instructor (4)

Instructor's preparation (5) Clarity of question answering

\section{Instructor - Rapport}

(1) Instructor sparks student (2) Instructor is pleasant (3) Instructor raises interest (4) Attainable outside classroom

\section{Course - Difficulty}

(1) Amount of content compared to time at disposal (2)

Difficulty of course (3) Amount of content compared to effort (4) Effort put in the course

Interaction

(1) Interactivity (2) Participation in the course

eLearning materials - Technology

(1) Visual appearance of WBTs (2) Visual appearance of videos (3) Interactivity of WBTs

eLearning materials - Flexibility

(1) WBTs supporting individual learning speed (2) WBTs supporting individual learning style (3) Videos supporting individual learning speed (4) Videos supporting individual learning style

\section{eLearning materials - Usefulness}

(1) WBTs helpful in recapitulating the lecture (2) WBTs as useful supplement of materials (3) Usage of WBTs (4)

Videos helpful in recapitulating the lecture (5) Usage of Videos (6) Skype consultation hour as useful supplement

Affective and motivational outcomes

(1) General interest in topics of the course (2) Lecture enhancing interest in the topic

\subsection{Evaluating learning outcomes}

The evaluation of learning outcomes is a complex field. Kraiger et al. (1993) note that there are three different kinds of learning outcomes: cognitive outcomes (such as factual knowledge), skill-based outcomes (such as proceduralization capabilities), and affective outcomes (such as attitudinal or motivational ones). Measurement depends on which kinds of outcomes are addressed [24].

Cognitive outcomes can be measured by power tests such as multiple choice tests. In this research, part of the final exam was implemented as a multiple choice test in order to measure factual knowledge acquisition.

But higher learning outcomes such as specific skills demand the learner not only to reproduce knowledge but also to take the right steps in solving a task and deciding which learned concepts are appropriate in a given situation. These skills can be measured through methods such as observations or hands-on testing. The latter means that a given task is evaluated with regard to whether a learner chooses and performs the right steps to solve the problem. In our case, this is exactly what an exam does. For example, in the final exam the students were required to develop a model such as an entity-relationshipdiagram to a given problem description. They now had to perform several steps: identifying the relevant entities, adding the right attributes and relations, and refining the diagram by using special constructs such as generalizations in order to avoid redundancy. All these steps were assessed, and scores were given with regard to the degree of task completion. Thus, skillbased outcomes are also part of the measurement of the exam.

Attitudinal and motivational outcomes refer to states of individuals that will affect how a person acts. For example, if a learner gains more selfconfidence throughout a course, he might be able to act faster and be more self-aware in future situations. However, these "softer" factors should not be confused with the motivation that learners feel during the course. Thinking that a course is interesting and that the instructor is doing a good job are not learning outcomes, but could be considered feedback on the overall course quality. Attitudinal and learning outcomes are usually measured through self-reports. In our case, attitudinal and motivational outcomes were not the focus of the research, but they were addressed by two items of the satisfaction questionnaire (see Table 1).

We chose exam scores as a measure for learning success. Since the exams had a similar proportion of content in each semester (with around one third 
multiple choice, one third modeling, and one third open questions), the scores (taken in points, not grades) were deemed to be a reasonably objective measurement tool for learning outcomes.

\section{Presentation of Results}

The results of our study are presented in this section. Since there are four different groups of students (one for each semester), results are chronologically related to groups one to four, with group one being the first group (winter term of 2008/2009) and group four the last (summer term 2010).

\subsection{Results with regard to learning outcomes}

The learning outcomes were measured by comparing mean results of the exam at the end of the semester. Students could reach a score from 0 to 82 points. Table 2 shows the actual results, together with the total number of WBTs available in each semester. A Kruskal-Wallis test of variance was conducted in SPSS, as well as a Median-test. Both tests show that differences are highly significant, with $\mathrm{p}<.001$.

Table 2. Comparison of exam results

\begin{tabular}{|l|r|r|r|r|r|}
\hline Group & N & $\begin{array}{l}\text { Mean } \\
\text { score }\end{array}$ & Variance* & Median** & $\begin{array}{c}\text { Total } \\
\text { WBTs } \\
\text { in use }\end{array}$ \\
\hline 1 & 155 & 34.365 & 15.621 & 35.500 & 0 \\
\hline 2 & 168 & 33.832 & 14.853 & 36.125 & 9 \\
\hline 3 & 178 & 38.479 & 13.585 & 40.750 & 18 \\
\hline 4 & 262 & 42.090 & 14.409 & 43.500 & 18 \\
\hline All & 763 & 37.860 & 14.965 & 39.500 & \\
\hline
\end{tabular}

* Significant with $\mathrm{p}<.001$ (Kruskal-Wallis Test)

** Significant with $\mathrm{p}<.001$ (Median Test)

The mean score at the beginning was around 34 points. While the scores in the second semester were a little lower, they increased in semester three and four by up to 42 points. In the first semester, there were no WBTs in use, since development started only at this point. In the second semester, the first nine student-produced WBTs were offered. However, they were not directly integrated into the LMS but placed on a separate website. Since integration did not work properly, there were issues such as layout problems (very small frames, e.g.).

These issues were overcome in the next semester when the total number of WBTs was increased to 18 that were directly placed on the LMS with adjustable screen sizes. While the results do not allow concluding any causal relations, it is still salient that in the first two semesters, when no WBTs were in use or they covered only some parts of the lecture, students performed the worst. At the time when 18 WBTs were used (which covered nearly all contents of the lecture) and properly implemented, student performance clearly increased.

The hypothesis that the increased performance can at least be partially ascribed to WBTs is supported by the results of the questionnaire, where many students reported that the materials were a beneficial supplement to the script. Since WBTs were not part of the learning materials at the beginning, the question items with regard to the eLearning quality were only implemented in the questionnaires of the third and fourth semesters. Table 3 presents the results of the eLearning quality items taken from the learning service satisfaction questionnaire (explained in detail in the next paragraph) of the fourth semester.

Table 3. Satisfaction with eLearning materials

\begin{tabular}{|c|c|c|c|}
\hline Dim & eLearning element & Mean & Variance \\
\hline \multirow{3}{*}{$\underset{\Xi}{\stackrel{\Xi}{\Xi}}$} & appearance wbts & 1.94 & .671 \\
\hline & appearance videos & 1.92 & .834 \\
\hline & interaction wbts & 2.08 & .786 \\
\hline \multirow{4}{*}{ 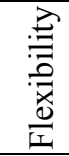 } & wbt - learning speed & 2.17 & 1,050 \\
\hline & wbt - learning style & 2.26 & 1.025 \\
\hline & video - learning speed & 1.83 & .813 \\
\hline & video - learning style & 1.95 & .979 \\
\hline \multirow{6}{*}{ 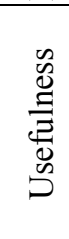 } & wbt - recapitulation & 1.91 & .983 \\
\hline & wbt - useful & 1.94 & .998 \\
\hline & wbt - usage & 2.46 & 1.101 \\
\hline & videos - recapitulation & 1.68 & .845 \\
\hline & videos - usage & 1.91 & 1.107 \\
\hline & skype - useful & 2.04 & 1.211 \\
\hline
\end{tabular}

The results in general can be considered to be quite good. The students rated the items on a Likert scale ranging from 1 (full agreement) to 5 (no agreement). Thus, a rating of 1.94 for the item "The WBTs are a useful supplement of the other learning materials" indeed seems promising. The recapitulation of contents, as well as the visual appearance and interactivity, reached similar results. This seems to support the theory that the eLearning materials were actually very popular and supported better learning outcomes. The lowest scores were reached by the items "WBTs support personal learning style" and "actual usage of WBTs." These items show quite high variances. This might hint at the fact that there are indeed different types of 
learners and learning styles, some of which value the WBTs, while others make less use of them.

\subsection{Results with regard to satisfaction}

Student satisfaction was measured with an online questionnaire. It was conducted at the end of the semester just before the exam, and thus participation was voluntary. The results (mean values) are shown in Table 4. Since our measures were iteratively improved and thus showed the strongest effects in the last semester, we also calculated the percentile increase (or decrease) of an item by comparing the fourth and the first semester. We also conducted a ttest of the variance and the medians of the different question items, comparing these semesters in order to check whether the increases were significant. Items that increased significantly are marked in Table 4. Details of the t-test are shown in Table 5 (please note that due to constraints of space, only factors that increased by nearly 10 percent or more are shown in the table).

Table 4. Results of satisfaction questionnaire

\begin{tabular}{|c|c|c|c|c|c|c|}
\hline \multirow[b]{2}{*}{ Dimension } & \multirow[b]{2}{*}{ Item } & \multicolumn{4}{|c|}{ Mean of Group } & \multirow{2}{*}{$\begin{array}{l}\text { Incr. } \\
(\%)\end{array}$} \\
\hline & & 1 & 2 & 3 & 4 & \\
\hline \multirow{4}{*}{$\begin{array}{l}\text { Course } \\
\text { overall }\end{array}$} & \multirow{4}{*}{$\begin{array}{l}\text { satisfaction } \\
\text { comparison } * \\
\text { innovativeness } \\
\text { recommendation }\end{array}$} & 2.7 & 2.4 & 2.6 & 2.4 & 9.6 \\
\hline & & 2.8 & 2.5 & 2.7 & 2.5 & 11.3 \\
\hline & & 2.3 & 2.2 & 2.1 & 2.0 & 11.8 \\
\hline & & 2.6 & 2.3 & 2.4 & 2.4 & 7.6 \\
\hline \multirow{5}{*}{$\begin{array}{l}\text { Course - } \\
\text { structure }\end{array}$} & \multirow{5}{*}{$\begin{array}{l}\text { structure * } \\
\text { content } * \\
\text { relevance } \\
\text { materials } \\
\text { transparency }\end{array}$} & 2.5 & 2.2 & 2.2 & 2.1 & 14.9 \\
\hline & & 2.9 & 2.7 & 2.8 & 2.6 & 10.1 \\
\hline & & 2.5 & 2.4 & 2.5 & 2.5 & -1.4 \\
\hline & & 2.4 & 2.3 & 2.1 & 2.1 & 11.9 \\
\hline & & 2.6 & 2.7 & 2.9 & 2.6 & 1.7 \\
\hline \multirow{5}{*}{$\begin{array}{l}\text { Instructor } \\
\text { Skill level }\end{array}$} & \multirow{5}{*}{$\begin{array}{l}\text { instructor } \\
\text { knowledge } \\
\text { explanations * } \\
\text { preparations } \\
\text { answers }\end{array}$} & 2.5 & 2.2 & 2.2 & 2.2 & 9.6 \\
\hline & & 1.3 & 1.3 & 1.2 & 1.2 & 4.5 \\
\hline & & 2.2 & 1.9 & 1.9 & 1.9 & 14.5 \\
\hline & & 1.4 & 1.4 & 1.4 & 1.4 & 5.0 \\
\hline & & 1.9 & 1.7 & 1.7 & 1.7 & 10.9 \\
\hline \multirow{4}{*}{$\begin{array}{l}\text { Instructor } \\
\text { Rapport }\end{array}$} & \multirow{4}{*}{$\begin{array}{l}\text { enthusiasm * } \\
\text { raising interest } * \\
\text { pleasant } \\
\text { attainability }\end{array}$} & 2.8 & 2.6 & 2.5 & 2.4 & 13.8 \\
\hline & & 2.8 & 2.4 & 2.5 & 2.4 & 16.0 \\
\hline & & 2.4 & 2.1 & 2.2 & 2.2 & 6.4 \\
\hline & & 2.2 & 2.0 & 2.2 & 2.2 & -1.9 \\
\hline \multirow{4}{*}{ Difficulty } & \multirow{4}{*}{$\begin{array}{l}\text { difficulty } \\
\text { ratio cont./eff. } \\
\text { ratio cont./time } \\
\text { effort } *\end{array}$} & 3.2 & 2.9 & 3.4 & 3.0 & 5.4 \\
\hline & & 3.3 & 3.2 & 3.6 & 3.2 & 4.6 \\
\hline & & 3.5 & 3.3 & 3.4 & 3.3 & 5.7 \\
\hline & & 2.4 & 2.3 & 2.3 & 2.2 & 10.6 \\
\hline \multirow{2}{*}{ Interaction } & \multirow{2}{*}{$\begin{array}{l}\text { interactivity } \\
\text { participation }\end{array}$} & 2.5 & 2.5 & 2.3 & 2.3 & 9.1 \\
\hline & & 2.3 & 2.4 & 2.6 & 2.3 & 0.6 \\
\hline \multirow{2}{*}{$\begin{array}{l}\text { Affective \& } \\
\text { Motiv. }\end{array}$} & \multirow{2}{*}{$\begin{array}{l}\text { interest } \\
\text { raising interest }\end{array}$} & 2.8 & 2.6 & 2.7 & 2.5 & 8.6 \\
\hline & & 3.1 & 2.8 & 2.9 & 2.7 & 11.5 \\
\hline
\end{tabular}

* Significant increase from semester 1 to 4
Many of the factors that we addressed directly (such as overall satisfaction, satisfaction with materials, contents, and interactivity) increased by about 0.3 points (very roughly estimated, coming to an increase of about $10 \%$ ). To check these increases for significance, the t-test conducted in SPSS first calculates the significance of the hypothesis that the variances of the variables are homogeneous (Table 5, first column). Next, two t-tests for the mean values were conducted - one for the case where the probability of variance homogeneity was not significant (first line of each item) and one for the other case (second line). The results of the two-tailed $\mathrm{t}$-test of the means are listed for both cases.

Statistically significant factors include the overall satisfaction compared to other lectures, satisfaction with content, explanations of the instructor, the degree to which the instructor managed to raise enthusiasm and further interest in the topic, and the effort students felt they had put into the course. Two of the most important items for our research, namely, the overall satisfaction and satisfaction with the learning materials, have not increased significantly, but they are at least nearly at a significant level (.077 and .069). Similar results can be identified for the perceived interactivity (.089). Taking into account both the percentile increase in satisfaction with the different aspects of the course, as well as results from the t-test, we assume that the supplementary materials indeed helped increase learners' satisfaction.

\section{Discussion of results and limitations}

In this paper we presented a concept on how to integrate students into the process of learning content production using IT tools and concepts. Students were encouraged to create true-false-items as part of the final exam. In a Web Engineering seminar they also created WBTs that were used as supplementary learning materials in the large scale lecture "Introduction to Business Informatics," thus making students co-designers of WBTs for their peers. Content creation was implemented as a coconstruction process between the students and instructors. The WBTs were then used in the lecture, and the questionnaire as well as exam results were gathered over four semesters. Results show a significant increase in learners' satisfaction as well as learning outcomes. We assume that these results are significantly caused by the new forms of interaction and implementation of the WBTs. Our assumptions are supported by the online questionnaires, where most students stated that the WBTs indeed were a useful supplementation to other materials. 
Table 5. Overview of significant results

\begin{tabular}{|l|c|c|c|c|}
\hline \multirow{2}{*}{ Item } & $\begin{array}{c}\text { Test of } \\
\text { Variance }\end{array}$ & \multicolumn{3}{|c|}{ T-Test of Means } \\
\cline { 2 - 5 } & Sig. & $\begin{array}{c}\text { Sig. } \\
\text { (biv.) }\end{array}$ & $\begin{array}{c}\text { Mean } \\
\text { Diff. }\end{array}$ & $\begin{array}{c}\text { Stand. } \\
\text { Error of } \\
\text { Diff. }\end{array}$ \\
\hline satisfaction & .042 & .086 & .254 & .147 \\
& & .077 & .254 & .143 \\
\hline comparison & .864 & $.032 *$ & .312 & .144 \\
& & .031 & .312 & .143 \\
\hline innovativeness & .127 & .075 & .273 & .152 \\
& & .072 & .273 & .151 \\
\hline structure & .008 & .014 & .369 & .149 \\
& & $.011 *$ & .369 & .144 \\
\hline content & .511 & $.043 *$ & .296 & .146 \\
& & .039 & .296 & .143 \\
\hline materials & .068 & .073 & .282 & .156 \\
& & .069 & .282 & .154 \\
\hline instructor & .078 & .164 & .238 & .170 \\
& & .154 & .238 & .166 \\
\hline explanations & .006 & .058 & .317 & .166 \\
& & $.049 *$ & .317 & .160 \\
\hline answers & .288 & .127 & .213 & .139 \\
& & .114 & .213 & .134 \\
\hline enthusiasm & .408 & $.033 *$ & .391 & .182 \\
& & .031 & .391 & .180 \\
\hline raising interest & .244 & $.011 *$ & .455 & .177 \\
& & .010 & .455 & .174 \\
\hline effort & .031 & .054 & .258 & .133 \\
& & $.047 *$ & .258 & .129 \\
\hline interactivity & .015 & .100 & .227 & .137 \\
& & .089 & .227 & .133 \\
\hline & & .059 & .351 & .185 \\
& & .057 & .351 & .183 \\
\hline
\end{tabular}

* Significant with $\mathrm{p}<.05$

There are, however, several limitations due to the nature of an action research approach. Working with real students in complex learning arrangements means that it is very difficult to identify causal relations. As we compare learning scenarios that are influenced by countless different factors, the usage of single tools or methods can hardly explain the outcomes on their own. For this reason, we cannot prove causal relations from the data thus far, as we cannot strictly exclude the influence of factors that were not addressed in this paper directly. Surely, the general approaches of the instructor and his staff to improve the lecture and the script will also have influenced the outcomes.

In addition, measuring learning outcomes by exam results is problematic, since the exams changed from semester to semester. Although the structure and rating scheme stayed similar, it cannot be guaranteed that the difficulty and rating were the same each semester.

Still, the significant increases strongly hint at the fact that the concept of co-construction does work. This result is important for researchers in the domain of pedagogy who are looking for new ways of learner integration and self-regulated learning. In addition, the methods of co-construction described in this paper can also be adapted by practitioners in their own lectures in order to create valuable content.

There is still much need for further improvements of the processes described. With regard to Web 2.0 technologies and trends such as Open Innovation, it seems reasonable to enhance the content creation and review process even more by use of these methods and tools. Also, raising interaction in the classroom with the use of mobile devices which allow digital content production seems very promising. Thus, we will develop our course further with the help of Web 2.0 and mobile devices in order to create a stronger sense of community and collaboration.

\section{References}

[1] M. Alavi, G. Marakas and Y. Yoo, "A Comparative Study of Distributed Learning Environments on Learning Outcomes", Information Systems Research, 13 (2002), pp. 404-415.

[2] H. An, S. Shin and K. Lim, "The effects of different instructor facilitation approaches on students' interactions during asynchronous online discussions", Computers \& Education, 53 (2009), pp. 749-760.

[3] L. W. Anderson, D. R. Krathwohl, P. W. Airasian, K. A. Cruikshank, R. E. Mayer, P. Pintrich, J. Raths and M. Wittrock, "A taxonomy for learning, teaching, and assessing: A revision of Bloom's taxonomy of educational objectives", (2000).

[4] B. Bantinic, K. Moser and B. Puhle, Der WWWFragebogengenerator, in W. Bandilla, B. Bantinic and L. Graef, eds., Online Research - Methoden, Anwendungen und Ergebnisse, Verlag fuer Psychologie Dr. C.J. Hogrefe, Goettingen, 1999, pp. 93 - 102.

[5] G. M. Bodner, "Constructivism - A Theory Of Knowledge", Journal of Chemical Education, 63 (1986), pp. 873-878.

[6] E. Chernobilsky, A. Nagarajan and C. E. Hmelo-Silver, Problem-based learning online: multiple perspectives on collaborative knowledge construction, Proceedings of th 2005 conference on Computer support for collaborative learning: learning 2005: the next 10 years!, International Society of the Learning Sciences, Taipei, Taiwan, 2005.

[7] P. A. Cohen, "Student ratings of instruction and student achievement: A meta-analysis of multisection validity studies", Review of Educational Research, 51 (1981), pp. 281-309.

[8] N. W. Coppola, S. R. Hiltz and N. Rotter, Becoming a virtual professor: pedagogical roles and ALN, System 
Sciences, 2001. Proceedings of the 34th Annual Hawaii International Conference on, 2001, pp. 1-10.

[9] A. Donabedian, "Evaluating the Quality of Medical Care", The Milbank Memorial Fund Quarterly, 44 (1966), pp. 166-206.

[10] R. M. Felder and L. K. Silverman, "Learning and teaching styles in engineering education", Engineering education, 78 (1988), pp. 674-681.

[11] J. A. Fitzsimmons and M. J. Fitzsimmons, Service management : operations, strategy, and information technology, McGraw-Hill/Irwin, Boston, 2005.

[12] A. Gadeib, Ansprueche und Entwicklung eines Systems zur Befragung ueber das World Wide Web, in W. Bandilla, B. Bantinic and L. Graef, eds., Online Research Methoden, Anwendungen und Ergebnisse, Verlag fuer Psychologie Dr. C.J. Hogrefe, Goettingen, 1999, pp. 103 111.

[13] R. M. Gagne, "Learning outcomes and their effects: Useful categories of human performance", American Psychologist, 39 (1984).

[14] I. Giannoukos, I. Lykourentzou, G. Mpardis, V. Nikolopoulos, V. Loumos and E. Kayafas, Collaborative elearning environments enhanced by wiki technologies, Proceedings of the $1 \mathrm{st}$ international conference on PErvasive Technologies Related to Assistive Environments, ACM, Athens, Greece, 2008.

[15] P. Goodyear, G. Salmon, J. Spector, C. Steeples and S. Tickner, "Competences for online teaching: A special report", Educational Technology Research and Development, 49 (2001), pp. 65-72.

[16] K. Goto and J. Schneider, "Learning through Teaching: Challenges and Opportunities in Facilitating Student Learning in Food Science and Nutrition by Using the Interteaching Approach", Journal of Food Science Education, 9 (2010), pp. 31-35.

[17] J. Grzega and M. Schöner, "The didactic model LdL (Lernen durch Lehren) as a way of preparing students for communication in a knowledge society", Journal of Education for Teaching, 34 (2008), pp. 167 - 175.

[18] P. Hauptmanns, Grenzen und Chancen von quantitativen Befragungen mit Hilfe des Internet, in W. Bandilla, B. Bantinic and L. Graef, eds., Online Research Methoden, Anwendungen und Ergebnisse, Verlag fuer Psychologie Dr. C.J. Hogrefe, Goettingen, 1999, pp. 21 38.

[19] P. J. H. Hu, W. Hui, T. H. K. Clark and K. Y. Tam, "Technology-assisted learning and learning style: A longitudinal field experiment", IEEE Transactions on Systems Man and Cybernetics Part a-Systems and Humans, 37 (2007), pp. 1099-1112.

[20] E. Kahiigi, L. Ekenberg and M. Hansson, Exploring the e-Learning State of art, Conference on E-Learning, Academic Conferences Limited, 2007, pp. 349-368.

[21] F. Ke, "Examining online teaching, cognitive, and social presence for adult students", Comput. Educ., 55 (2010), pp. 808-820.

[22] K. P. King, "Identifying success in online teacher education and professional development", The Internet and Higher Education, 5 (2002), pp. 231-246.

[23] A. Y. Kolb and D. A. Kolb, "Learning styles and learning spaces: Enhancing experiential learning in higher education", Academy of Management Learning \& Education, 4 (2005), pp. 193-212.

[24] K. Kraiger , J. K. Ford and E. Salas, "Application of cognitive, skill-based, and affective theories of learning outcomes to new methods of training evaluation", Journal of Applied Psychology (1993), pp. 311-328.

[25] Kultusministerkonferenz, Prognose der Studienanfänger, Studierenden und Hochschulabsolventen bis 2020, Bonn, 2005.

[26] M. Mohr and H. Krcmar, Bildungscontrolling: State of the Art und Bedeutung für die IT-Qualifizierung, Technische Universität München, Lehrstuhl für Wirtschaftsinformatik, Garching b. München, 2005.

[27] M. G. Moore, "Editorial: Three types of interaction", American Journal of Distance Education, 3 (1989), pp. 1-7. [28] OECD, The Sources of Economic Growth in OECD Countries, Organisation for Economic Co-Operation and Development, 2003.

[29] J. Olmsted III, "The mid-lecture break: When less is more", Journal of Chemical Education, 76 (1999), pp. 525.

[30] S. Ozkan and R. Koseler, "Multi-dimensional students' evaluation of e-learning systems in the higher education context: An empirical investigation", Computers \& Education, 53 (2009), pp. 1285-1296.

[31] S. Peacock and J. Hooper, "E-learning in physiotherapy education", Physiotherapy, 93 (2007), pp. 218-228.

[32] G. Piccoli, R. Ahmad and B. Ives, Web-BasedVirtual Learning Environments: A Research Framework And A Preliminary Assessment Of Effectiveness In Basic IT Skills Training, MIS Quarterly, MIS Quarterly \& The Society for Information Management, 2001, pp. 401-426.

[33] P.-C. Sun, R. J. Tsai, G. Finger, Y.-Y. Chen and D. Yeh, "What drives a successful e-Learning? An empirical investigation of the critical factors influencing learner satisfaction", Computers \& Education, 50 (2008), pp. 11831202.

[34] G. I. Susman and R. D. Evered, "An assessment of the scientific merits of action research", Administrative science quarterly, 23 (1978), pp. 582-603.

[35] V. Thurmond and K. Wambach, "Understanding interactions in distance education: A review of the literature", International Journal of Instructional Technology and Distance Learning (2004).

[36] K. Topping, "Peer assessment between students in colleges and universities", Review of Educational Research, 68 (1998), pp. 249-276.

[37] R. Wegener, P. Menschner and J. M. Leimeister, Analyse und Optimierung von Lehrdienstleistungen mittels Service Blueprinting - Konzeption und erste empirische Befunde, Multikonferenz Wirtschaftsinformatik (MKWI) 2010, Göttingen, 2010.

[38] Wissenschaftsrat, Empfehlungen zum arbeitsmarktund demographiegerechten Ausbau des Hochschulsystems, Wissenschaftsrat, Berlin, 2006. 